\title{
Métodos para a Superação de Dormência da Tarumarana
}

\section{Methods for Overcoming Dormancy of Tarumarana}

\author{
Cristiane Ramos Vieira*a; Joás dos Santos Soares ${ }^{\mathrm{b}}$; Bruno Conceição de Veigac; Maicon Marinho Vieira Araujo ${ }^{\mathrm{b}}$; \\ Rayza Samara de Assis Carneiro ${ }^{\mathrm{a}}$
}

\author{
aUniversidade de Cuiabá, Programa de Pós-Graduação Stricto Sensu em Ciências Ambientais. MT, Brasil. \\ bUniversidade de Cuiabá, Faculdade de Agronomia. MT, Brasil. \\ ${ }^{c}$ Universidade Federal de Mato Grosso, Programa de Pós-Graduação Stricto Sensu em Agronomia. MT, Brasil. \\ *E-mail: cris00986@hotmail.com
}

\begin{abstract}
Resumo
A tarumarana (Buchenavia tomentosa Eichler) é uma espécie florestal com potencial para a recomposição florestal no bioma Cerrado. No entanto, a formação das mudas dessa espécie, via semente, fica comprometida, por esta apresentar dormência tegumentar. Com base nessa problemática, desenvolveu-se um experimento com o objetivo de avaliar a escarificação ácida e a imersão em água, como métodos para a superação da dormência de pirênios de tarumarana. Os tratamentos testados foram: T0 - sem tratamento para superação da dormência; T1 - imersão em água quente por uma hora; T2 - imersão em água quente por uma hora e meia; T3 - imersão em água quente por duas horas; T4 - imersão em ácido sulfúrico por uma hora; T5 - imersão em ácido sulfúrico por uma hora e meia. O experimento foi realizado em delineamento inteiramente casualizado, com 20 pirênios de tarumarana por repetição. Ao final de 30 dias, a contar do começo das emergências, foram avaliadas as seguintes variáveis: índice de velocidade de germinação (IVG), o tempo médio de germinação (TMG), porcentagem de germinação $(\mathrm{G})$ e o índice de velocidade de germinação (IVG), comprimento da parte aérea $(\mathrm{H})$ e diâmetro de coleto (DC). O método mais eficiente para a superação da dormência dos pirênios de tarumarana foi a imersão em água quente por uma hora e meia, que garantiu a maior taxa de germinação. No entanto, a imersão em água quente, como método para superação da dormência de pirênios de tarumarana, não influenciou de forma significativa no crescimento inicial em altura e em diâmetro das mudas obtidas.
\end{abstract}

Palavras-chave: Buchenavia Tomentosa. Ácido Sulfúrico. Água Quente. Quebra de Dormência. Semente Florestal.

\begin{abstract}
Tarumarana (Buchenavia tomentosa Eichler) is a forest species with potential for restoration in the Cerrado biome. However, the formation of seedlings of this species, via seed, is compromised, because it presents integumentary dormancy. Based on this problem, an experiment was developed with the objective of evaluating acid scarification and immersion in water, as methods for overcoming dormancy in tarumarana pyrenes. The tested treatments were: T0 - without treatment to overcome dormancy; T1 - immersion in hot water for one hour; T2 - immersion in hot water for one hour and a half; T3 - immersion in hot water for two hours; T4 - immersion in sulfuric acid for one hour; T5 - immersion in sulfuric acid for one hour and a half. The experiment was carried out in completely randomized design, with 20 pyrenes of tarumarana per repetition. At the end of 30 days, counting from the beginning of emergencies, the following variables were evaluated: germination speed index (IVG), average germination time (TMG), germination percentage $(G)$, the germination speed index (IVG), shoot length $(H)$ and diameter (DC). The most efficient method for overcoming dormancy in tarumarana pyrenes was immersion in hot water for one hour and a half, which guaranteed the highest germination percentage. However, immersion in hot water, as a method to overcome dormancy of tarumarana pyrenes, did not influence, significantly, the initial growth in height and diameter of the seedlings obtained.
\end{abstract}

Keywords: Buchenavia tomentosa. Sulfuric Acid. Hot Water. Breaking Dormancy. Forest Seed.

\section{Introdução}

As áreas que possuem vegetação típica do Cerrado brasileiro vêm passando, nas últimas décadas, por sucessivos processos de desmatamento, seja para abertura de novas áreas agrícolas, agropecuárias, ou pela retirada ilegal de madeira, como relatado por MMA (2020). Um dos problemas derivados desse desmatamento é a retirada de indivíduos arbóreos com potencial econômico e/ou necessários para a manutenção das espécies da fauna local. Dentre esses indivíduos está a Buchenavia tomentosa Eichler, conhecida vulgarmente como tarumarana ou mirindiba, uma espécie florestal pertencente à família Combretaceae (CORREA et al., 2020).

A tarumarana é uma espécie de ocorrência natural no
Cerrado, nas fitofisionomias cerradão e mata latifoliada semidecídua. Apresenta potencial apícola e é recomendada para a restauração florestal em áreas degradadas, devido a grande procura dos seus frutos pela fauna regional (AZEVEDO et al., 2015). Portanto, há necessidade de estimular a reposição de indivíduos dessa espécie, para que, dessa forma, as áreas desmatadas sejam efetivamente recuperadas.

No entanto, produzir mudas ou promover a recomposição florestal da tarumarana, via semente, pode ser um processo demorado, já que a espécie produz sementes com dormência e que, de acordo com Farias et al. (2015), não germinam mesmo com as primeiras chuvas.

Uma semente que possui dormência poderá apresentar as primeiras germinações após meses da sua semeadura, caso 
não se faça tratamento prévio. Além disso, sua germinação pode se dar de maneira desuniforme, consequência também relatada por Kosera Neto et al. (2015) e Dutra et al. (2017). $\mathrm{O}$ que não é interessante para um viveiro de produção de mudas, por exemplo. Por isso, anteriormente à semeadura, há que se obter informações a respeito da semente que a espécie de interesse produz. Caso esta apresente dormência, será necessário empregar algum método para a sua superação.

A dormência em sementes é atribuída, usualmente, a tegumentos impermeáveis, à imaturidade fisiológica ou à colheita recente (CASTRO et al., 2017). No caso da tarumarana, a dormência apresentada é a tegumentar. De acordo com Abreu et al. (2017) e Castro et al. (2017) esse tegumento impede à entrada de água e de oxigênio, o que impossibilita o crescimento do embrião. Dessa forma, não ocorre a germinação da semente.

Vários são os métodos empregados para a superação da dormência tegumentar, dentre os quais se têm a escarificação mecânica e química (DUTRA et al., 2012). Para isso, podese utilizar a lixa e o ácido sulfúrico, respectivamente, por serem as técnicas que frequentemente apresentam os melhores resultados quanto à taxa germinativa em espécies florestais (ARAÚJO et al., 2017).

Alguns trabalhos que empregaram a utilização do ácido sulfúrico para superar a dormência de sementes de espécies florestais têm demonstrado sua eficiência. Pereira et al. (2016) verificaram que a dormência de sementes de Stryphnodendron pulcherrimum (falso barbatimão) pode ser superada com a escarificação com ácido sulfúrico por 10 ou 12 minutos. No caso da Adenanthera pavonina (tento vermelho) são necessários 10 a 20 minutos (ARAÚJO NETO et al., 2012). Enquanto, para sementes de Piptadenia moniliformis (angicode-bezerro) (SILVA et al., 2017) e de Hymenaea courbaril (jatobá) (SOUZA; SEGATO, 2016), são necessários 20 minutos.

No entanto, a imersão das sementes ou frutos em água, quente ou fria ou em combinação entre as duas temperaturas, também pode ser utilizada como método para superar a dormência proporcionada pelo tegumento em sementes de espécies florestais. Oliveira et al. (2018) verificaram a eficiência da imersão em água a $100^{\circ} \mathrm{C}$, por cinco minutos, para superar a dormência em sementes de Delonix regia (Flamboyan). Em sementes de Mimosa setosa (sansão-deminas) a recomendação foi para imersão em água quente a 70 ou $80^{\circ} \mathrm{C}$ por três ou cinco minutos (SPERANDIO et al., 2013). Enquanto, para sementes de Guazuma ulmifolia (mutamba), Silva et al. (2016) recomendaram a imersão em água quente a $70^{\circ} \mathrm{C}$.

Diante disso, o presente experimento foi realizado com o objetivo de avaliar a escarificação ácida e a imersão em água, como métodos para a superação da dormência de pirênios de Buchenavia tomentosa.

\section{Desenvolvimento}

\subsection{Metodologia}

O experimento foi realizado na casa de vegetação da Faculdade de Agronomia da Universidade de Cuiabá, situada no campus Beira Rio I, em Cuiabá - MT, nas coordenadas $15^{\circ} 37^{\prime} 28^{\prime}$ 'S e $56^{\circ} 05^{\prime} 11^{\prime \prime} \mathrm{O}$. O clima predominante da região é o tropical de savana, segundo classificação de Köppen.

Os frutos de tarumarana foram coletados, ao chão, sob árvores matrizes, escolhidas aleatoriamente, localizadas na Universidade Federal de Mato Grosso, campus Cuiabá, nas coordenadas $15^{\circ} 36^{\prime} 36^{\prime \prime}$ S e 56 $6^{\circ} 03^{\prime} 57^{\prime \prime}$ O. A coleta se deu por um período de sete dias, e os frutos coletados foram aqueles não atacados por pragas. Após coleta, os frutos foram deixados em água por 48 horas para amolecimento da parte carnosa e facilitar sua retirada, mantendo, dessa forma, os pirênios (tegumento e embrião). Os pirênios que ficaram sobrenadantes foram descartados, já que estes, em geral, não germinam. Segundo Brasil (2009) o teste de flutuação é aplicado, a princípio, para a separação de sementes que contém endosperma e embrião, chamadas de sementes cheias, das sementes que apresentam nenhum ou algum tecido residual em sua composição, conhecidas essas como sementes vazias

Para os tratamentos em que se utilizou a água para a superação da dormência, os pirênios de tarumarana foram colocados em um béquer com capacidade para $500 \mathrm{~mL}$, com água, em câmara BOD regulada para temperatura de $70^{\circ} \mathrm{C}$. Onde permaneceram, por uma hora; uma hora e meia; e duas horas, num total de 20 pirênios para cada repetição dentro de cada tratamento. Enquanto, para os tratamentos em que se utilizou o ácido sulfúrico, os pirênios foram submetidos à imersão em solução contendo $80 \%$ de $\mathrm{H}_{2} \mathrm{SO}_{4}$. Sendo 20 pirênios imersos por uma hora e mais 20 por uma hora e meia, para cada repetição.

Dessa forma, os tratamentos testados foram: T0 tratamento controle (pirênios não submetidos ao tratamento); $\mathrm{T} 1$ - pirênios imersos por uma hora em água quente a $70^{\circ} \mathrm{C}$; $\mathrm{T} 2$ - pirênios imersos por uma hora e meia em água quente a $70^{\circ} \mathrm{C}$; T3 - pirênios imersos por duas horas em água quente a $70{ }^{\circ} \mathrm{C}$; T4 - pirênios imersos por uma hora a uma solução $80 \% \mathrm{H}_{2} \mathrm{SO}_{4}$; $\mathrm{T} 5$ - pirênios imersos por uma hora e meia a uma solução $80 \% \quad \mathrm{H}_{2} \mathrm{SO}_{4}$. O delineamento experimental utilizado foi o inteiramente casualizado, tendo, portanto, cinco repetições com 20 pirênios em cada tratamento.

Após os tratamentos para superação da dormência, os pirênios foram colocados em sacos de cultivo de 10x20 cm, preenchidas, com aproximadamente, 500 gramas de substrato comercial Basaplant $\AA$. Segundo o fornecedor, esse substrato é composto por casca de pinus, fibra de coco, turfa fibrosa, vermiculita, NPK e micronutrientes.

As primeiras germinações foram observadas com 30 dias após os tratamentos com superação de dormência, iniciandose, nesse momento, as avaliações realizadas no experimento. Para a germinação, considerou-se a plântula com os cotilédones 
totalmente desprendidos do tegumento. Foram avaliados: o índice de velocidade de germinação (IVG), calculado pela fórmula de Maguire (1962): IVG $=\mathrm{G} 1 / \mathrm{N} 1+\mathrm{G} 2 / \mathrm{N} 2+\ldots \mathrm{Gn} /$ $\mathrm{Nn}$. Onde IVG = índice de velocidade de germinação; G1, $\mathrm{G} 2, \ldots \mathrm{Gn}=$ número de plântulas normais germinadas a cada dia; $\mathrm{N} 1, \mathrm{~N} 2, \ldots \mathrm{Nn}=$ número de dias da semeadura à primeira, segunda até a última contagem.

O tempo médio de germinação (TMG), calculado pela fórmula: $\mathrm{TMG}=(\Sigma$ niti $) / \Sigma$ ni. Onde: ni $=$ número de sementes germinadas por dia; $\mathrm{ti}=$ tempo de incubação; $\mathrm{i}=1 \rightarrow 50$ dias. A germinação $(\mathrm{G})$, dada pela fórmula: $\mathrm{G}(\%)=(\mathrm{N} / 100) \mathrm{x}$ 100 , onde: $\mathrm{N}=$ número de sementes germinadas ao final do teste. E, a velocidade média de germinação (VMG), dada pela fórmula $\mathrm{VMG}=1 / \mathrm{t}$ em que: $\mathrm{t}$ = tempo médio de germinação.

Após 30 dias a partir da contagem da primeira germinação, foram realizadas as medidas da altura das plantas, com régua graduada, e do diâmetro de coleto, com paquímetro digital.

Os dados foram interpretados por meio da análise de variância e a comparação de médias foi realizada pelo método de Tukey ao nível de 5\% de probabilidade de erro utilizando o programa estatístico SISVAR, após constatação da normalidade dos dados.

\subsection{Resultados e Discussão}

Os resultados para os efeitos dos tratamentos testados para superar a dormência da tarumarana estão apresentados no Quadro 1. Observa-se que, para os tratamentos 4 (imersão em ácido sulfúrico por uma hora) e 5 (imersão em ácido sulfúrico por uma hora e meia) não houve a apresentação de resultados porque nenhuma germinação foi constatada nesses tratamentos durante todo o experimento. Portanto, pode-se dizer que, a concentração do ácido sulfúrico e/ou o tempo em que os pirênios de tarumarana ficaram imersos no mesmo, podem ter inviabilizado a atividade embrionária, não sendo possível a germinação nesses tratamentos.

Quadro 1 - Índice de velocidade de germinação (IVG), tempo médio de germinação (TMG, em dias), velocidade média de germinação $(\mathrm{VMG})$, germinação $(\mathrm{G}$, em \%), altura das plantas $(\mathrm{H}$, em $\mathrm{cm})$ e diâmetro de colo das plantas (DC, em mm), após teste de superação de dormência com água e ácido sulfúrico $\left(\mathrm{H}_{2} \mathrm{SO}_{4}\right)$

\begin{tabular}{|c|c|c|c|c|c|c|}
\hline Tratamento & IVG & TMG & VMG & G & H & DC \\
\hline T0 & $3,37 \mathrm{~d}$ & $5,52 \mathrm{a}$ & $0,18 \mathrm{c}$ & $40,0 \mathrm{c}$ & $7,45 \mathrm{a}$ & $2,29 \mathrm{a}$ \\
\hline T1 & $5,29 \mathrm{a}$ & $3,38 \mathrm{~b}$ & $0,29 \mathrm{~b}$ & $65,0 \mathrm{~b}$ & $8,35 \mathrm{a}$ & $2,36 \mathrm{a}$ \\
\hline T2 & $4,49 \mathrm{c}$ & $2,75 \mathrm{c}$ & $0,36 \mathrm{a}$ & $80,0 \mathrm{a}$ & $8,80 \mathrm{a}$ & $2,53 \mathrm{a}$ \\
\hline T3 & $5,16 \mathrm{~b}$ & $3,38 \mathrm{~b}$ & $0,29 \mathrm{~b}$ & $65,0 \mathrm{~b}$ & $9,45 \mathrm{a}$ & $2,62 \mathrm{a}$ \\
\hline T4 & $0,0 \mathrm{e}$ & $0,0 \mathrm{~d}$ & $0,0 \mathrm{~d}$ & $0,0 \mathrm{~d}$ & $0,0 \mathrm{~b}$ & $0,0 \mathrm{~b}$ \\
\hline T5 & $0,0 \mathrm{e}$ & $0,0 \mathrm{~d}$ & $0,0 \mathrm{~d}$ & $0,0 \mathrm{~d}$ & $0,0 \mathrm{~b}$ & $0,0 \mathrm{~b}$ \\
\hline CV $(\%)$ & 0,35 & 3,12 & 10,36 & 3,30 & 25,95 & 12,15 \\
\hline
\end{tabular}

T0 - sem tratamento para superação da dormência; T1 - imersão em água quente por uma hora; T2 - imersão em água quente por uma hora e meia; T3 - imersão em água quente por duas horas; T4 - imersão em ácido sulfúrico por uma hora; T5 - imersão em ácido sulfúrico por uma hora e meia. Médias seguidas de mesma letra não diferem significativamente, pelo teste Tukey a $5 \%$ de probabilidade.

A utilização do ácido sulfúrico também não foi eficiente para a germinação de $H$. courbaril, em alguns dos períodos de imersão que foram testados, conforme constatado por Souza e Segato (2016). Para estes autores, alguns tratamentos com imersão de ácido sulfúrico não foram eficientes porque o ácido pode ter sido absorvido pela semente e danificado a reserva da semente e/ou o eixo embrionário resultando em plântulas menos vigorosas. De acordo com Padilha et al. (2018) o sucesso para a superação da impermeabilidade do tegumento de sementes de várias espécies florestais com ácidos, está relacionado com a espécie e ao tempo de exposição da semente ao ácido. Por isso, a necessidade de produzir conhecimento que seja específico. Segundo Dousseau et al. (2007), frequentemente os ácidos são utilizados em sua forma concentrada, porém, mesmo em concentrações baixas, são prejudiciais. Isso pode ocorrer em razão de algumas sementes terem certa porosidade, permitindo uma rápida absorção do ácido, o que causa um efeito nocivo ao embrião.

Outra explicação foi dada por Ronchi et al. (2016) em estudo com a Bauhinia forficata (pata-de-vaca), onde verificaram que, o tratamento com imersão em ácido sulfúrico por 5 minutos proporcionou o maior valor de condutividade de elétrica, apontando que esse tratamento afetou a integridade das membranas, o que as danificou, comprometendo diretamente a qualidade fisiológica da semente e o desenvolvimento das plântulas da espécie estudada. O que também parece ter ocorrido no presente caso.

Para outras espécies florestais, a imersão em ácido sulfúrico também não se mostrou eficiente para a superação de dormência das sementes. Como nos casos da germinação de B. forficata (RONCHI et al., 2016); do Schizolobium parahyba (guapuruvu) (CANDIDO; OLIVEIRA, 2018); da Acacia mangium (acácia) (FERNANDES et al., 2018); e do Schizolobium amazonicum (paricá) (CARVALHO et al., 2019). Além disso, deve-se considerar que o uso de ácido sulfúrico tem algumas restrições, tais como: aquisição do ácido, possibilidade de acidentes durante o manuseio e ainda a destinação adequada dos resíduos gerados (BRANCALION et al., 2011). Por isso, nem sempre sua utilização é favorável, dando-se preferência por outros métodos, que sejam menos perigosos.

Dessa forma, os únicos tratamentos que apresentaram 
resultados que puderam ser analisados estatisticamente, foram aqueles em que se utilizou a água quente como método para a superação da dormência dos pirênios de tarumarana. Analisando o IVG verifica-se que, a imersão em água quente por uma hora (T1) e a imersão em água quente por duas horas foram os mais eficientes dos métodos empregados. Nesses tratamentos as médias observadas foram 36,3\% e 34,7\%, superiores em relação ao obtido no tratamento testemunha. Sendo assim, nos tratamentos 1 e 3 , as sementes germinaram com maior rapidez e facilidade. Essa informação é de grande importância técnica, uma vez que o IVG e o TMG são instrumentos para a avaliação do vigor e capacidade germinativa das sementes, além de servirem como indicativos de um menor ou maior tempo de permanência das mudas no viveiro (DUTRA et al., 2017). Nesse caso, a água quente se mostrou um método eficiente, além disso, ressalta-se que, a espécie é responsiva aos tratamentos pré-germinativos aplicados, portanto, para que se faça a produção de mudas de tarumarana, há a necessidade de utilizar de métodos para superar a dormência dos pirênios.

A exposição da semente em água quente é uma técnica que busca permeabilizar o tecido tegumentar e propiciar o surgimento de fissuras que permitam a absorção de água para desencadear o processo germinativo (PACHECO; MATOS, 2009; SPERANDIO et al., 2013; SOUSA et al., 2019). Rodrigues et al. (2008) comenta que esse método tem a baixo custo, facilidade de manuseio e menor tempo de execução, sendo, portanto, recomendado para uso pelos viveiristas. De acordo com Schmidt (2000), a eficiência do uso da água quente depende da espécie, da temperatura da água e do tempo de imersão durante a escarificação.

As primeiras germinações foram observadas no tratamento 1, porém, em menor quantidade que no tratamento 2 (imersão em água quente por uma hora e meia). Em T2, as sementes começaram a germinar depois, porém, após começarem, germinaram mais rapidamente, isso se refletiu nas médias de TMG. Para essa variável, as sementes do tratamento testemunha foram as que precisaram de mais tempo para germinar, o que corrobora que, há a necessidade de empregar algum método para a superação da dormência dos pirênios de tarumarana, caso se pretenda a produção de mudas dessa espécie em maiores quantidades. De acordo com Santana e Ranal (2000), quanto menor for o tempo médio de germinação maior será a velocidade de germinação das sementes, haja vista que são duas grandezas inversamente proporcionais. O menor TMG é vantajoso para o processo de germinação, já que as plântulas podem se estabelecer mais rapidamente, aproveitando as condições ambientais favoráveis (NOGUEIRA et al., 2010). Dessa forma, se considerar os tratamentos com germinações, os menores períodos entre as germinações ocorreram em T2; seguido de T1 e T3 que apresentaram as mesmas médias. Verifica-se que, a média no tratamento controle foi 50,2\% superior em relação a de T2. Isso porque, apesar de a germinação ter ocorrido, no tratamento testemunha, antes que, em T2, o intervalo entre uma germinação e outra foi maior no tratamento testemunha.

Quando o processo germinativo iniciou em T2 (três dias após ter começado em T1), o intervalo entre uma germinação e outra foi menor, ocorrendo, dessa forma, com maior rapidez, isso fez com que, a média para o VMG, nesse tratamento, fosse a maior. A média em T2 foi $50 \%$ superior em relação ao observado no tratamento testemunha. Seguida das médias em T1 e T3, onde a média para VMG foi semelhante e 37,9\% superior em relação à testemunha.

De acordo com Crisóstomo et al. (2020) a velocidade de germinação está associada à velocidade da entrada de água na semente, e, consequentemente, a ativação dos processos metabólicos. Ao romper o tegumento protetor do embrião aumenta-se a taxa de sementes germinadas e promovendo velocidade de emergência, e consequentemente acelera a produção de mudas (COELHO; RIBEIRO, 2018). Guedes et al. (2013) citam que as sementes que germinam mais rapidamente tendem a desenvolver plântulas com maior comprimento, onde a redução de tempo de germinação e emergência pode resultar em maior sucesso no estabelecimento e na ocupação de uma área. Corroborando a eficiência da imersão em água como método de superação de dormência para a espécie estudada.

Quando as germinações começaram, em T2, ocorreram com maior rapidez entre uma germinação e outra e, em maior número também. Sendo assim, o maior percentual de germinação ocorreu nesse tratamento, atingindo média de $80 \%$. Enquanto, no tratamento testemunha este percentual foi de 40 , incrementando em $50 \%$ no T2. Segundo Leão et al. (2009), valores entre o intervalo de 80 a $98 \%$ de germinação em sementes de espécies florestais nativas são considerados ótimos. Portanto, para a produção de mudas de tarumarana, a imersão de suas sementes em água quente por uma hora e meia, é o método mais eficiente para superar a dormência e aumentar sua taxa de germinação. E, dessa forma, ser possível produzir mais mudas.

Outros autores também verificaram a eficiência da água quente no processo de superação de dormência de sementes de espécies florestais. Sousa et al. (2019) recomendaram o tratamento com imersão de sementes de Apeiba tibourbou (pau-jangada) em água quente a $100^{\circ} \mathrm{C}$. Dutra et al. (2017) recomendaram a imersão de sementes de Peltophorum dubium (canafístula) em água quente a $95^{\circ} \mathrm{C}$. Lima et al. (2013) recomendaram a imersão das sementes de D. regia em água quente a $80{ }^{\circ} \mathrm{C}$ por cinco minutos. Enquanto Oliveira et al. (2018) recomendaram a imersão em água quente a $100^{\circ} \mathrm{C}$ para a mesma espécie por cinco minutos.

Bezerra et al. (2018) que constataram que o tratamento com imersão dos diásporos de Tectona grandis (teca) em água quente a $100{ }^{\circ} \mathrm{C}$ por 5 minutos, propiciou um percentual de emergência significativamente maior que os demais tratamentos. Ao passo que, Ronchi et al. (2016) verificaram que a imersão de sementes de B. forficata em água por 48 horas foi o que propiciou os melhores resultados, atingindo 
média de $97,75 \%$.

Quanto ao crescimento inicial das mudas, não se observou significância entre as médias, a final da análise de germinação, tanto para o crescimento inicial em altura quanto para o crescimento em diâmetro. No entanto, verifica-se que, em T3, a média para o crescimento em altura foi $21,2 \%$ superior em relação à obtida no tratamento testemunha e; em T2 a média foi $15,3 \%$ superior. De acordo com Carvalho e Nakagawa (2012) o desenvolvimento inicial em plântulas é consequência das reservas provenientes da semente. Sendo que, a altura é uma característica que informa sobre a qualidade da muda e se correlaciona positivamente com o crescimento no campo (GOMES; PAIVA, 2011).

Para o crescimento em diâmetro, a média em T3 foi $12,6 \%$ superior em relação à média na testemunha e; em T2 foi $9,5 \%$ superior. Segundo Souza et al. (2006) mudas com o maior incremento em diâmetro possuem maior capacidade de formação e de crescimento de novas raízes. O que garante maior capacidade de pegamento no campo. Dessa forma, ressalta-se que, quando o método para superação de dormência dos pirênios de tarumarana for a imersão em água quente, este não influenciou para um crescimento em altura e diâmetro, que seja significativo, ao comparar os períodos de imersão de uma hora, uma hora e meia ou por duas horas. No entanto, a imersão em água quente por uma hora e meia permite obter mais mudas, em função da maior quantidade de sementes germinadas.

\section{Conclusão}

Os pirênios da tarumarana apresentaram dormência superada com a imersão em água quente, pelo período de uma hora e meia, garantindo maior taxa de germinação.

A imersão em água quente, como método para superação da dormência de pirênios de tarumarana, não influenciou de forma significativa no crescimento inicial em altura e em diâmetro das mudas.

\section{Referências}

ABREU, D.C.A. et al. Métodos de superação da dormência e substratos para germinação de sementes de Tachigali vulgaris L.G. Silva \& H.C. Lima. Flor. Amb., v.24, p.1-10, 2017. doi:10.1590/2179-8087.071814

ARAUJO NETO, A.C. et al. Ácido sulfúrico na superação da dormência de sementes de Adenanthera pavonina L. Sci. Plen., v.8, n.4, p.1-5, 2012

ARAÚJO, A.V.; SILVA, M.A.D.; FERRAZ, A.P.F. Superação de dormência de sementes de Libidibia ferrea (Mart. ex Tul.) L.P. Queiroz var. ferrea. Mag., v.29, n.3/4, p.298-304, 2017.

AZEVEDO, M.I.R.; PAIVA, H.N.; GOMES, J.M. Efeitos de substratos, luz e temperatura na germinação de sementes de Buchenavia tomentosa Eichler (merindiba) em condições de laboratório. Agri-env. Sci., v.1, n.1, p.11-22, 2015.

BEZERRA, L.A.S.; MORAES, S.A.F.; OLIVEIRA, G.P. Superação de dormência em diásporos em Tectona grandis. An. Aca. Pern. Ciên. Agr., v.15, n.2, p.139-144, 2018.
BIANCHETTI, A. Produção e tecnologia de sementes de essências florestais. Curitiba: Embrapa, 1981.

BRANCALION, P.H.S.; MONDO, V.H.V.; NOVEMBRE, A.D.L. Escarificação química para a superação da dormência de sementes de saguaraji-vermelho (Colubrina glandulosa Perk. Rhamnaceae). Rev. Árv., v.35, n.1, p.119-124, 2011. doi: 10.1590/ S0100-67622011000100014

BRASIL. Ministério da Agricultura, Pecuária e Abastecimento. Regras para análise de sementes. Ministério da Agricultura, Pecuária e Abastecimento. Secretaria de Defesa Agropecuária. Brasília: MAPA/ACS, 2009. 395 p.

BRASIL. Ministério do Meio Ambiente. O bioma cerrado. 2020. Disponível em: https:/www.mma.gov.br/biomas/cerrado.html.

CANDIDO, D.F.; OLIVEIRA, A.S. Métodos para a superação da dormência em sementes de Schizolobium parahyba (Vellozo) S.F. Blake (Fabaceae). Act. Biol. Cat., v.5, n.2, p.98-105, 2018. doi: 10.21726/abc.v5i2.451

CARVALHO, N. M.; NAKAGAWA, J. Sementes: Ciência, Tecnologia e Produção. $5^{\text {a }}$ ed. Jaboticabal: FUNEP, 2012. 590 p.

CARVALHO, M.B.F. et al. Métodos de superação de dormência da Schizolobium amazonicum Huber ex Ducke. Braz. J. Ani. Env. Res., v.2, n.1, p.490-500, 2019. doi: 10.1590/S010131222006000300016

CASTRO, D.S. et al. Caracterização da testa de sementes de Apuleia leiocarpa (Vogel) J.F.Macbr) após superação de dormência. CiênC. Flor, v.27, n.3, p.1061-1068, 2017. doi: $10.5902 / 1980509828681$

COELHO, T.B.; RIBEIRO, V.A. Superação de dormência em sementes de jatobá. Ipê Agr. Jour., v.2, n.1, p.14-22, 2018.

CORREA, A.R. et al. Germination and seed ecology of Buchenavia tomentosa Eichler (Combretaceae). J. Seed Sci., v.42, p.1-11, 2020. doi: 10.1590/2317-1545v42223782

CRISÓSTOMO, N.M.S. et al. Emergência de plântulas de Colubrina glandulosa Perkins após superação da dormência. Rev. Craib. Agroec., v.5, n.1, p.1-5, 2020.

DOUSSEAU, S. et al. Superação de dormência em sementes de Zeyheria montana Mart. Ciênc. Agrot., v.31, n.6, p.1744-1748, 2007. doi: 10.1590/S1413-70542007000600021

DUTRA, T.R. et al. Emergência e crescimento inicial da canafístula em diferentes substratos e métodos de superação de dormência. Rev. Caat., v.25, n.2, p.65-71, 2012.

DUTRA, T.R. et al. Superação de dormência e substratos alternativos com serragem na germinação e crescimento inicial de mudas de Peltophorum dubium (Spreng.) Taub. Agrop. Cient. Sem., v.13, n.2, p.113-120, 2017.

FARIAS, J. et al. Seed dispersal and predation of Buchenavia tomentosa Eichler (Combretaceae) in a Cerrado sensu stricto, midwest Brazil. Braz. J. Biol., v.75, n.4, p.88-96, 2015. doi: 10.1590/1519-6984.06214

FERNANDES, H.E. et al. Quebra de dormência em Acacia magium Willd e Ormosia arborea (Vell.) Harms. Ciênc. Agr., v.16, n.2, p.73-79, 2018. doi: 10.28998/rca.v16i2.4103

GOMES, J.M.; PAIVA, H.N. Viveiros florestais. Viçosa: Editora UFV, 2011. 116p. (Série Didática).

GUEDES, R. S. et al. para superar dormência de sementes de Cassia fistula L. Rev. Biot., v.26, n.4, p. 11-22, 2013. doi: $10.5007 / 2175-7925.2013 \mathrm{v} 26 \mathrm{n} 4 \mathrm{p} 11$

KOSERA NETO, C. et al. Métodos para superação de dormência em sementes de tomateiro arbóreo (Solanum betaceum). Pesq. 
Agrop. Trop., v.45, n.4, p.420-425, 2015. doi: 10.1590/1983$40632015 \mathrm{v} 4537332$.

LEÃO, N. et al. Tecnologia de sementes de espécies florestais nativas da Amazônia. Belém: Embrapa Amazônia Oriental, 2009.

LIMA, J.S. et al. Métodos de superação de dormência em sementes de flamboyant (Delonix regia). Rev. Ver., v.8, n.1, p.104109, 2013.

MAGUIRE, J.D. Speed of germination in selection and evolution for seedling emergence and vigor. Crop Sci., v.2, p.176-177, 1962. doi: 10.2135/cropsci1962.0011183X000200020033x

NOGUEIRA, F.C.B.; MEDEIROS. S.F.O.; GALLÃO, M.I. Caracterização da germinação e morfologia de frutos, sementes e plântulas de Dalbergia cearensis Ducke (pau-violeta) - Fabaceae. Act Bot. Bras., v.24, n.4, p.978-985, 2010. doi: 10.1590/S010233062010000400013

OLIVEIRA, K.J.B. et al. Quebra de dormência de sementes de Delonix regia (Fabaceae). Rev. Ciên. Agr., v.41, n.3, p.709-716, 2018. doi: 10.19084/RCA17302

PACHECO, M.V.; MATOS, V.P. Método para superação de dormência tegumentar em sementes de Apeiba tibourbou Aubl. Rev. Bras. Ciênc. Agr., v.4, n.1, p.62-66, 2009. doi: 10.5039/ agraria.v4i1a10

PADILHA, M.S.; SOBRAL, L.S.; ABREU, L. Métodos para a superação da dormência em sementes de Cassia leptophylla Vogel. Ciênc. Agr., v.16, n.2, p.1-8, 2018. doi: 10.28998/rca. v16i2.4154

PEREIRA, A.G.; CRUZ, E.D.; BARROS, H.S.D. Methods for overcoming dormancy in Stryphnodendron pulcherrimum seeds. Pesq. Flor. Bras., v.36, n.87, p.195-199, 2016. doi: 10.4336/2016. pfb.36.87.931

RODRIGUES, A.P.D.C. et al. Tratamentos para superar a dormência de sementes de Acacia mangium Willd. Act. Scient.
Agron., v.30, n.2, p.279-283, 2008.

RONCHI, H.S. et al. Superação de dormência tegumentar de sementes da pata de vaca (Bauhinia forficata Link). Enc. Bio., v.13, n.3, p.1291-1297, 2016. doi: 10.18677/Enciclopedia Biosfera_2016_114

SANTANA, D.G.; RANAL, M.A. Análise estatística na germinação. Rev. Bras. Fis. Veg., v.12 (Edição Especial), p.205237, 2000.

SILVA, D.L. et al. Emergência e estabelecimento de plântulas de Guazuma ulmifolia Lam. em função de diferentes tratamentos pré-germinativos. Ciênc. Flor., Santa Maria, v.26, n.3, p.763-772, 2016. doi: 10.5902/1980509824205

SILVA, J.N. et al. Temperatura influenciando a germinação de sementes de Piptadenia moniliformis submetidas a superação de dormência. J. Env. Anal. Prog., v.2, n.4, p.412-420, 2017. doi: 10.24221/jeap.2.4.2017.1458.412-420

SCHMIDT, L. Dormancy and pretreatment. In: OLSEN, K. (Ed.). Guide to handling of tropical and subtropical forest seed. Humlebaek: Danida Forest Seed Centre, 2000. p.263-303.

SOUSA, H.G.A. et al. Superação da dormência de sementes de Apeiba tibourbou Aubl. J. Biotech. Biod., v.7, n.2, p.320-324, 2019. doi: $10.20873 /$ jbb.uft.cemaf.v7n2.sousa

SOUZA, C.A.M.; OLIVEIRA, R.B.; LIMA, J.S.S. Crescimento em campo de espécies florestais em diferentes condições de adubação. Ciêncl. Flor., v.16, n.3, p.243-249, 2006. doi: 10.5902/198050981905

SOUZA, V.M.S.; SEGATO, S.V. Superação de dormência de sementes de jatobá (Hymenaea courbaril L.). Nuc., v.13, n.1, p.71-80, 2016.

SPERANDIO, H.V.; LOPES, J.C.; MATHEUS, M.T. Superação de dormência em sementes de Mimosa setosa Benth. Comum. Sci., v.4, n.4, p.385-390, 2013. 